\title{
A Study of Rapid Serological Diagnosis of Ramichloridium mackenziei 653 Isolated Strain Using Counter Immunoelectrophoresis Technique
}

\section{Fadwa Alshareef*}

Department of Clinical Laboratory Science, College of Applied Medical Science, King Saud University, Riyadh, K.S.A

*Corresponding Author: Fadwa Alshareef, Department of Clinical Laboratory Science, College of Applied Medical Science, King Saud University, Riyadh, K.S.A.

Email: fadoalshareef@ksu.edu.sa
Received: March 15, 2021

Published: April 22, 2021

(C) All rights are reserved by Fadwa Alshareef.

\section{Abstract}

Background: Ramichloridium mackenziei cause cerebral phaeohyphomycosis found to be highly neurotropic mostly endemic to the middle east.

Objectives: The aim of the study is to develop a simple and rapid technique for the diagnosis of Cerebral phaeohyphomycosis by preparing protein antigen from the Ramichloridium mackenziei 653 isolated strain.

Materials and Methods: Ramichloridium mackenziei 653 isolated strain from the patients suffering with Cerebral phaeohyphomycosis and were grown on neutral Sabouraud dextrose agar (N-SDA) and broth culture filtrate antigen was prepared and followed by counter immune-electrophoresis.

Results: Ramichloridium mackenziei 653 isolated strain purified fractions (PFs) of antigen and and the collected sera of the patient suffering with cerebral phaeohyphomycosis showed good precipitation lines.

Conclusion: The present study could be helpful in the development of rapid serological diagnosis of Ramichloridium mackenziei infections based on our invitro results.

Keywords: Ramichloridium mackenziei 653; Counter Immune-electrophoresis; Broth Culture Filtrate Antigen; Purified Fractions

\section{Abbreviations}

PFs: Purified Fractions; CIE: Counter Immunoelectrophoresis; BCFA: Broth Culture Filtrate Antigen; N-SDB: Neutral Sabouraud Dextrose Broth; CBB: Coomassie Brilliant Blue

\section{Introduction}

Neurotropic dematiaceous fungi reported to cause cerebral phaeohyphomycosis and is being recognized as an opportunistic infection in immunocompromised patients [1-3].
In Saudi Arabia, the brain abscesses caused by an unusual phaeohyphomycete classified as $R$ amichloridium mackenziei species which were isolated from four cases of brain abscesses from the Central Province of Saudi Arabia was first reported by Campbell and Al-Hedaithy, this fungus has a limited geographic distribution, as it has been considered the cause of these four cases in Saudi Arabia and another four cases in other Middle Eastern countries [4] and in another case study two cases of cerebral phaeohyphomycosis were reported caused by Ramichloridium mackenziei in the Eastern Province of Saudi Arabia [5]. 
As reported in previous study, Rhinocladiella mackenziei (formerly Ramichloridium mackenziei) one of the rare etiologic agent of cerebral phaeohyphomycosis was found to be highly neurotropic [6] it appears to be endemic to the Middle East and may possibly be geographically restricted to this area $[4,7]$.

Moreover, Ramichloridium mackenziei infection appears to occur predominantly in the Middle East and to target the brain exclusively [8-10] and it has not been recovered from any environmental source [10]. Outside of the Middle East two cases has been reported from India and Afghanistan [11,12].

In the previous research study, a case of cerebral phaeohyphomycosis was found to be reported in a 56-year-old Egyptian male who worked as a mason in Kuwait for 6 years, computerized tomography scan of the brain revealed presence of a large abscess in the left occipital lobe and aspirated pus was cultured and Ramichloridium mackenziei species was grown in the culture [7].

In the previous research report, Ramichloridium obovoideum was found to be recognized as causative agent of cerebral abscesses in a 58-year-old Kuwaiti woman, with a history of chronic renal failure, where computed tomography demonstrated multiple, ringenhancing, cerebral lesions in the deep left parieto-occipital region [13].

Cerebral phaeohyphomycosis caused by Rhinocladiella mackenziei (formerly Ramichloridium mackenziei), causes fatal brain infections with a high mortality rate. In a case study, a 64 year old Saudi female patient, was admitted initially to a long term care facility with chronic respiratory failure and dependence on the mechanical ventilation, she developed left sided weakness and a CT-scan of the brain revealed multiple variable sized hypodense, well-defined lesions with ring enhancement, stereotactic needle aspiration of the largest lesion showed fungal hyphae and final culture grew Rhinocladiella mackenzie, treatment was initially started on liposomal amphotericin B, then voriconazole and caspofungin intravenously but the patient failed to respond to antifungal therapy and finally she died 34 days after the start of the treatment [14].

Another case was reported in a 59-year-old Qatari female patient, who was suffering with breast carcinoma, she developed brain abscess while receiving chemotherapy for carcinoma of the breast, diagnosis was performed by craniotomy, aspiration of the brain abscess and direct microscopy showed dematiaceous fungal hyphae and Rhinocladiella mackenziei was recovered in culture and this identification was confirmed by molecular analysis and histopathological examination of the tissue from the brain biopsy revealed moniliform hyphae characteristic for phaeohyphomycosis. However, the patient failed to respond to antifungal therapy with amphotericin B and voriconazole or amphotericin B and posaconazole and finally expired 64 days after diagnosis [15].

As Cerebral phaeohyphomycosis caused by Ramichloridium mackenziei species is a rare disease, but it is very challenging one with high mortality rate, particularly when the central nervous system is affected, as the diagnosis is mainly depending on a high index of clinical suspicion along with CT-scan and accurate mycological examination of the clinical samples. However, there is an urgent requirement of rapid and timely diagnostic method for early diagnosis of the disease and for deciding treatment protocols.

The present research study was performed to develop a simple and rapid technique for the diagnosis of Cerebral phaeohyphomycosis by preparing protein antigen from the Ramichloridium obovoideum ("Ramichloridium mackenziei") 653 isolated strain which were taken from King Faisal Specialist hospital and Research center (KFSH\&RC) [16] and the sera of the patient suffering with cerebral phaeohyphomycosis was tested against the isolated protein antigen. This technique will be useful in the diagnosis of phaeohyphomycosis caused by Ramichloridium mackenziei species and may be useful in follow up the patients during treatment.

\section{Materials and Methods}

\section{Collection of pathogen}

Ramichloridium mackenziei 653 isolated strain from the patients suffering with Cerebral phaeohyphomycosis were collected from (Dr. Hail M Al-Abdely), King Faisal Specialist hospital and Research center (KFSH\&RC).

\section{Culturing of Ramichloridium mackenziei 653 isolated strain}

Ramichloridium mackenziei 653 isolated strain were grown on neutral Sabouraud dextrose agar (PDA) (glucose 20g/L, peptone $10 \mathrm{~g} / \mathrm{L}$ and agar $20 \mathrm{~g} / \mathrm{L}$, at $\mathrm{p}^{\mathrm{H}} 7.0$ ) medium plates for 15 days at $37^{\circ} \mathrm{C}$. The morphology of the cultures was carefully observed and typical colonies only were selected for the preparation of antigen. Surface growth was washed with sterile $0.85 \%$ normal saline and was filtered through layers of sterile glass wool. 


\section{Broth culture filtrate antigen (BCFA) preparation}

The method of antigen preparation was the same as that described in thesis of Fadwa 0 Al-shareef [17]. After 15 days growth of the fungal culture approximately half of the agar surface, the colony morphology of the culture was carefully observed and 6-10ml neutral Sabouraud Dextrose broth (N-SDB) were added to the agar culture. The mycelia were scraped from the plate and transferred to a universal bottle. The lid was screwed down tightly and the content homogenized using a vortex mixer. Two-three $\mathrm{ml}$ of the mycelium suspension were immediately transferred to 1-liter flask containing $500 \mathrm{ml}$ of $\mathrm{N}$-SDB with magnetic stirrer. The inoculated flasks were incubated at $37^{\circ} \mathrm{C}$ under continuous stirring for 21 days. The fungus was killed by the addition of merthiolate to the final concentration $0.02 \%(\mathrm{w} / \mathrm{v})$ and the flasks left at $4^{\circ} \mathrm{C}$ overnight. The broth was separated from the mycelium by filtration through Whatman No.1 paper (Whatman Limited, England) placed in a Buckner funnel. The broth was centrifuged (Beckman, USA) at $10,000 \mathrm{~g}$ for $30 \mathrm{~min}$ at $4^{\circ} \mathrm{C}$. The supernatant was collected and filtered through $0.22 \mathrm{~mm}$ Nalgene filter. The filtrate was frozen, lyophilized and stored at $-7^{\circ} \mathrm{C}$ until it is used. Three patched of BCFA were prepared in this manner. This is designed as the BCFA. The mycelium was washed three times with sterile distilled water, weighed and frozen at $-70^{\circ} \mathrm{C}$ until processed.

\section{Counter immunoelectrophoresis (CIE)}

This procedure was performed same as the method followed in Fadwa $0 \mathrm{Al}$-shareef thesis [17]. Three to four $\mathrm{ml}$ of $1 \%$ agarose in veronal buffer $\mathrm{p}^{\mathrm{H}} 8.6$ (solution, $5 \mathrm{~A}$ ), was layered over a glass slide ( $3 \times 1$ inch). Two wells ( $3 \mathrm{~mm}$ in diameter) in two rows ( $1 \mathrm{~cm}$ apart) were punched in the gel. The purified fractions (PFs) antigen well diameter was 4-mm. the wells near the cathode were filled with the antigen and those near the anode with the sera. The sera were used in each well. The slides were placed in an electrophoresis chamber (Beckman, USA). Disposable wicks were used to bridge the gel with the veronal buffer. A current of $4 \mathrm{~mA}$ at a voltage of 75-100 V was applied to the maximum 8 slide for ( $60 \mathrm{~min}$ ). Precipitin lines were stained with CBB (solution 5B). The agarose slides were soaked overnight in veronal buffer and allowed to dry at $60{ }^{\circ} \mathrm{C}$ in a hot oven for (3h) with filter paper covering it. These were stained for $5-15 \mathrm{~min}$ and de-stained using the same solution without the stain.

\section{Results}

Ramichloridium mackenziei 653 isolated strain purified fractions (PFs) of antigen were obtained by broth culture filtrate an- tigen preparation was used as antigen protein and the collected sera of the patient suffering with cerebral phaeohyphomycosis was taken and performed counter immunoelectrophoresis (CIE) and the Precipitation lines were observed when stained with CBB (solution 5B) (Figure 1).

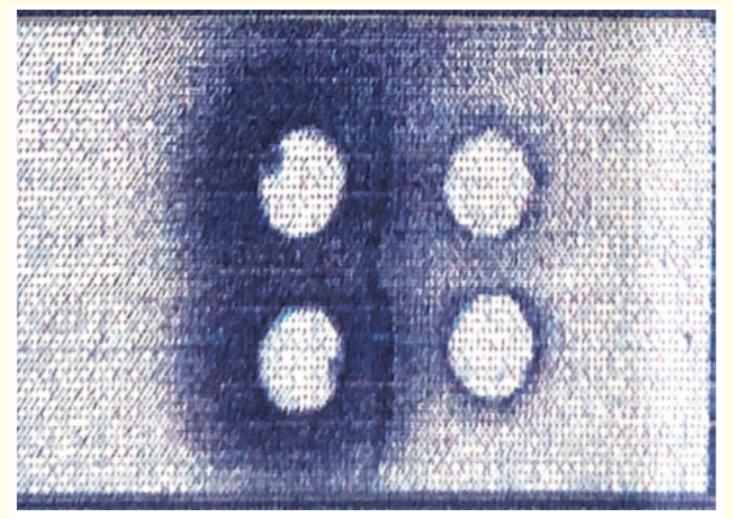

Figure 1: Precipitation lines of purified fractions (PFs) of antigen and antisera of the patients suffering with Rhinocladiella mackenziei infection.

\section{Discussion}

Rhinocladiella mackenziei causes infection of the central nervous system and a challenging disease with a high mortality rate, rapid and serological diagnostic test is needed for early diagnosis and treatment of this serious infection. The present study has been done purifying the protein antigen from Ramichloridium mackenziei 653 strain, which has been isolated from the patients and the antisera of the infected person is being used to perform counter immunoelectrophoresis serological test and the lines of precipitation had been observed (Figure 1). Counter immunoelectrophoresis has been widely used in the detection of protein and antibody reactions reported in previous studies $[18,19]$, in contrast we have observed we have observed good precipitation lines in our present research work.

\section{Conclusion}

In conclusion, present study could be helpful in the development of rapid serological diagnosis of Ramichloridium mackenziei infections based on our invitro experiments and result, further in- 
vestigation will be carry out in isolation of protein from the Ramichloridium mackenziei and performing serological test.

\section{Acknowledgement}

The authors acknowledge the support of grant from the "Research Center of the Female Scientific and Medical Colleges", Deanship of Scientific Research, King Saud University for supporting this research project.

\section{Authors Contribution}

Fadwa Alshareef-Planning and designing the complete research project work, designing methodology, performed experimental work and writing manuscript and editing.

\section{Conflict of Interest}

None.

\section{Bibliography}

1. LU AS and de Hoog GS. "Infections of the central nervous Kantarciog system by melanized fungi: a review of cases presented between 1999 and 2004". Mycoses 47 (2004): 4-13.

2. Revankar SG., et al. "Primary central nervous system phaeohyphomycosis: a review of 101 cases". Clinical Infectious Diseases 38 (2004): 206-216.

3. Garzoni C., et al. "Cladophialophora bantiana: a rare cause of fungal brain abscess. Clinical aspects and new therapeutic options". Medical Mycology 46 (2008): 481-486.

4. Campbell CK and Al-Hedaithy SSA. "Phaeohyphomycosis of the brain caused by Ramichloridium mackenziei sp. nov. in Middle Eastern countries". Journal of Medical and Veterinary Mycology 31 (1993): 325-332.

5. Kashgari TQ., et al. "Cerebral phaeohyphomycosis caused by Ramichloridium mackenziei in the Eastern Province of Saudi Arabia”. Annals of Saudi Medicine 20 (2000): 457-460.

6. Arzanlou M., et al. "Phylogenetic and morphotaxonomic revision of Ramichloridium and allied genera". Study Mycology 58 (2007): 57-93.

7. Khan ZU., et al. "Additional case of Ramichloridium mackenziei cerebral phaeohyphomycosis from the Middle East". Medical Mycology 40.4 (2002): 429-433.
8. Amr SS and Al-Tawfiq JA. "Aspiration cytology of brain abscess from a fatal case of cerebral phaeohyphomycosis due to Ramichloridium mackenziei". Diagnostic Cytopathology 35 (2007): 695-699.

9. Alkhunaizi AM., et al. "Invasive fungal infections in living unrelated renal transplantation". Transplantation Proceedings 37 (2005): 3034-3037.

10. Al-Abdely HM., et al. "Successful therapy of cerebral phaeohyphomycosis due to Ramichloridium mackenziei with the new triazole Posaconazole". Medical Mycology 43 (2005): 91-95.

11. Badali H., et al. "First autochthonous case of Rhinocladiella mackenziei cerebral abscess outside the Middle East". Journal of Clinical Microbiology 48 (2010): 646-649.

12. Cristini A., et al. "Cerebral phaeohyphomycosis caused by Rhinocladiella mackenziei in a woman native from Afghanistan". Journal of Clinical Microbiology 48 (2010): 3451-3454.

13. Podnos YD., et al. "Cerebral phaeohyphomycosis caused by Ramichloridium obovoideum (Ramichloridium mackenziei): case report”. Neurosurgery 45.2 (1999): 372-375.

14. Al-Tawfiq JA and Boukhamseen A. "Cerebral phaeohyphomycosis due to Rhinocladiella mackenziei (formerly Ramichloridium mackenziei): case presentation and literature review". Journal of Infection and Public Health 4.2 (2011): 96-102.

15. Saad J Taj-Aldeen., et al. "Cerebral phaeohyphomycosis due to Rhinocladiella mackenziei (formerly Ramichloridium mackenziei): a taxonomic update and review of the literature". Medical Mycology 48.3 (2010): 546-556.

16. Hail M Al-Abdely., et al. "SCH 56592, Amphotericin B, or Itraconazole Therapy of Experimental Murine Cerebral Phaeohyphomycosis Due toRamichloridium obovoideum ("Ramichloridium mackenziei"). Antimicrobial Agents and Chemotherapy 44.5 (2000): 1159-1162.

17. Fadwa Obaid Suliman Al-Shareef. "Purification and characterization of the broth culture filtrate antigen of the pathogen Madurella mycetamatis (Masters Thesis)". Department of clinical laboratory science, college of applied medical science, King Saud university, Riyadh, Saudi Arabia (2001). 
18. Necidová L E., et al. “Counter immunoelectrophoresis: a simple method for the detection of species-specific muscle proteins in heat-processed products". Veterinární Medicína 47.5 (2002): 143-147.

19. Ninna W Berg. "Rapid detection of infectious bursal disease antibodies by counter immunoelectrophoresis". Avian Pathology 11.4 (1982): 611-614.

\section{Assets from publication with us}

- Prompt Acknowledgement after receiving the article

- Thorough Double blinded peer review

- Rapid Publication

- Issue of Publication Certificate

- High visibility of your Published work

Website: www.actascientific.com/

Submit Article: www.actascientific.com/submission.php

Email us: editor@actascientific.com

Contact us: +919182824667 